\title{
Mechanism of Electrodeposition Process of Poly(Ethylene Glycol) Diamine to Titanium Surface
}

\author{
Osamu Fukushima ${ }^{1}$, Yusuke Tsutsumi ${ }^{2}$ and Takao Hanawa ${ }^{1, *}$ \\ ${ }^{1}$ Institute of Biomaterials and Bioengineering, Tokyo Medical and Dental University, Tokyo 101-0062, Japan \\ ${ }^{2}$ Research Center for Structural Materials, National Institute for Materials Science, Tsukuba 305-0047, Japan
}

\begin{abstract}
Electrodeposition of biofunctional molecules is effective in adding biofunction to metals; however, the mechanism of electrodeposition remains unclear. We consider the electrodeposition process of poly(ethylene glycol) (PEG) to the pure titanium surface, in which the termination of both PEG terminals proceeds with $\mathrm{NH}_{2}$ (PEG-diamine; MW: 1000). To elucidate this process, the thickness and mass change of the deposited layer and the electron transfer during electrodeposition was investigated using quartz crystal microbalance (QCM), ellipsometry, and cyclic voltammetry. Consequently, surface electric charge directly influenced the adsorption of PEG-diamine and unmodified PEG molecules. PEGdiamine was attracted to QCM electrode containing Ti (Ti-QCM electrode) and condensed on the surface by cathodic charge, by which electron transfer from PEG-diamine to the Ti surface occurred. Bonding of PEG-diamine with the Ti surface by electrodeposition was strong with no detachment from Ti. PEG-diamine was immediately adsorbed onto the Ti surface by the weak electrostatic force and bonded randomly via this force. Subsequent rearrangement and condensation occurred alongside a electrochemical reaction between the molecules and the Ti surface due to cathodic charge. Consequently, PEG-diamine molecules do not firmly remain on the Ti surface under electrodeposition, but shake near the Ti surface while undergoing repeated ionization and un-ionization. [doi:10.2320/matertrans.MT-M2020111]
\end{abstract}

(Received April 8, 2020; Accepted April 27, 2020; Published June 25, 2020)

Keywords: titanium, PEG, electrodeposition, surface electric charge, cathodic reaction

\section{Introduction}

At present, over $70 \%$ of the implant devices in medicine still consist of metals because of their high strength, toughness, and durability. Further, it is difficult to immediately replace the metals in medical devices with ceramics or polymers. A disadvantage of using metals as biomaterials is that they are typically artificial materials with no biofunction. To add biofunction to metals, surface modification is effective. Surface modification is an important and predominant technique for obtaining biofunction and biocompatibility in metals for biomedical applications. One surface modification technique is a process that changes the surface composition, structure, and morphology of a material, while not altering the bulk mechanical properties. A tremendous number of surface modification techniques using dry and wet processes to improve the hard tissue compatibility of titanium have been developed. ${ }^{1-7)}$ A second approach is the immobilization of biofunctional molecules to the metal surface to control the adsorption of proteins and adhesion of cells, platelets, and bacteria. ${ }^{8)}$

Poly(ethylene glycol) (PEG) is an oligomer or polymer of ethylene oxide; however, historically, PEG has tended to refer to oligomers and polymers with a molecular weight below 20,000 . It is coupled to hydrophobic molecules to produce non-ionic surfactants. This property, combined with the availability of PEGs with a wide range of end-functions, contributes to the wide use of PEGs in biomedical research in drug delivery, tissue engineering scaffolds, surface functionalization, and many other applications. ${ }^{9)}$ PEG is a biofunctional molecule onto which the adsorption of proteins is inhibited. Therefore, the immobilization of PEG to a metal surface is an important tool to biofunctionalize the metal surface.

*Corresponding author, E-mail: hanawa.met@tmd.ac.jp
We have employed an electrodeposition technique to immobilize PEG on the titanium (Ti) surface. For the electrodeposition of PEG to the Ti surface, both terminals of PEG are terminated with $-\mathrm{NH}_{2}$ (PEG-diamine; MW: 1000). The cathodic potential was charged to $\mathrm{Ti}$ from the open circuit potential (OCP) to $-5.0 \mathrm{~V}$ vs. a saturated calomel electrode $(\mathrm{SCE})\left(\mathrm{V}_{\mathrm{SCE}}\right)$ and is maintained at this potential for 300 s. During charging, PEG-diamine electrically migrates to and is deposited on the Ti cathode. More terminated amines combine with $\mathrm{Ti}$ oxide as $\mathrm{NH}-\mathrm{O}$ bonds by electrodeposition, and PEG-diamine is immobilized as a loop-shape or U-shape. Meanwhile, more amines randomly exist as $\mathrm{NH}_{3}{ }^{+}$in the PEG-diamine layer formed by immersion. ${ }^{10,11)}$ The amount of PEG-diamine immobilized on the metals is governed by the concentrations of the active hydroxyl groups on each surface oxide in the case of electrodeposition and governed by the relative permittivity of the surface oxide in the case of immersion. ${ }^{12)}$ The PEG-immobilized surface inhibits the adsorption of proteins and attachment of cells, as well as the adhesion of platelets ${ }^{13)}$ and bacteria, ${ }^{14,15)}$ indicating that this electrodeposition technique is useful for the biofunctionalization of metal surfaces. In addition, to immobilize RGD peptide on the electrodeposited PEG on Ti, PEG with an $-\mathrm{NH}_{2}$ group and a $-\mathrm{COOH}$ group $\left(\mathrm{NH}_{2}-\mathrm{PEG}-\mathrm{COOH}\right)$ was employed. One terminal group, $-\mathrm{NH}_{2}$, must bind stably with a surface oxide on the metal. Meanwhile, the other terminal group, $-\mathrm{COOH}$, can usefully bond to biofunctional molecules, such as RGD. ${ }^{16)}$ This RGD/PEG/Ti surface accelerates calcification by the MC3T3-E1 cell. ${ }^{17)}$ Calcification is strongest on the RGD/PEG/Ti surface, and bone formation on the $\mathrm{RGD} / \mathrm{PEG} / \mathrm{Ti}$ surface is accelerated compared to that on the $\mathrm{RGD} / \mathrm{Ti}$ surface in rabbit. ${ }^{18)}$ Meanwhile, graft- and loop-type PEGs were formed on mirror-polished $\mathrm{Ti}$ surfaces using electrodeposition with mono- and diamine-functionalized PEGs, and a Velcro-like friction behavior could be induced by simply changing the 
<smiles>COCCOCCOCCCN</smiles>

Fig. 1 Chemical structure of PEG-diamine.

conformation of the PEGs. ${ }^{19)}$ In addition, electrodeposition is applied to 2-methacryloyloxyethyl phosphorylcholine (MPC) polymers to inhibit platelet adhesion to the Ti surface..$^{20,21)}$

As mentioned above, the electrodeposition of a biofunctional molecule is effective in improving the biofunction of metals. However, the mechanism of electrodeposition is still unclear; thus, we made the best effort to elucidate the electrodeposition process and mechanism through the investigation of the change in thickness and mass of the deposited layer, and the transfer of electrons during electrodeposition by quartz crystal microbalance (QCM), ellipsometry, and cyclic voltammetry techniques. This research will enhance our understanding of the electrodeposition phenomenon of functional molecules to metal surfaces and promote further advanced electrodeposition techniques.

\section{Materials and Methods}

\subsection{Preparation of PEG-diamine solution}

We have employed a characteristic PEG molecule in which both terminals of PEG were terminated with $\mathrm{NH}_{2}$ (PEGdiamine; PEG1000 Diamine, NOF Corporation, Tokyo, Japan). The chemical formula of PEG-diamine is shown in Fig. 1. PEG-diamine was dissolved in $0.3-\mathrm{mol} \mathrm{L}^{-1} \mathrm{NaCl}$ solution made from deionized water (Millipore) at a concentration of $0.02-\mathrm{mol} \mathrm{L}^{-1}$, and the $\mathrm{pH}$ of the solution was adjusted to $\mathrm{pH} 3$ and 11 by $1-\mathrm{mol} \mathrm{L}^{-1} \mathrm{HCl}$. The original PEG without termination (Unmodified-PEG; NOF Corporation, Tokyo, Japan) was used for comparison with the QCM technique. Unmodified-PEG was dissolved in deionized water with a concentration of $0.02-\mathrm{mol} \mathrm{L}^{-1}$, and the $\mathrm{pH}$ of the solution was adjusted to $\mathrm{pH} 3$ and 11 .

\subsection{Adsorption behavior of PEG-diamine using QCM and an ellipsometer}

To investigate the adsorption behavior of PEG-diamine onto Ti when $\mathrm{Ti}$ is immersed in PEG-diamine solution, the mass change of $\mathrm{Ti}$ electrode during immersion in PEGdiamine solution and Unmodified-PEG solution was monitored using QCM. Commercially pure Ti was sputterdeposited on QCM electrode (quartz crystal of the A-T cut type, Hokuto Denko, Japan) with a fundamental resonant frequency of $6 \mathrm{MHz}$ (Ti-QCM electrode). The exposed area of $\mathrm{Ti}$ to the solution was $1.33 \mathrm{~cm}^{2}$. When the crystal is made to oscillate at its resonant frequency, the fundamental frequency changes, as the mass is adsorbed onto or desorbed from the electrode. The frequency shift $(\Delta f)$ was monitored by an electrochemical QCM controller (model HQ101B, Hokuto Denko, Tokyo, Japan) connected to an electrochemical analysis system (model HZ-3000, Hokuto Denko, Tokyo, Japan). Ti-QCM electrode was immersed in $0.3-\mathrm{mol} \mathrm{L}^{-1}$
$\mathrm{NaCl}$ solution, and the $\Delta f$ of the crystal was stabilized in the solution for $10 \mathrm{~min}$ before the injection of PEG-diamine solution. After $10 \mathrm{~min}$, concentrated PEG-diamine solution was injected with a syringe at a concentration of 2 mass $\%$. The $\Delta f$ of the crystal at $37^{\circ} \mathrm{C}$ was monitored for $24 \mathrm{~h}$.

After QCM measurement, specimens were rinsed in the deionized water and dried, followed by measurement using an ellipsometer (DVA-36Ls, Mizojiri Optical Co., Tokyo, Ltd.) in air to determine the thickness of the adsorbed and remaining PEG-diamine molecule layer. The use of the ellipsometer resulted in the underestimation of the thickness compared with that in solution. The light source was a He-Ne laser with a wavelength of $632.8 \mathrm{~nm}$, and the incident angle to the titanium surface was $70^{\circ}$. The thickness was calculated by optical constants - the refractive index and absorption coefficient of $\mathrm{TiO}_{2}$ with the $\mathrm{Ti}$ substrate were 2.209 and $3.079,22,23)$ and those of the $\mathrm{Ti}$ substrate were 2.22 and $2.99,{ }^{24)}$ respectively.

\subsection{Electrodeposition behavior of PEG-diamine using QCM}

In this experiment, another type of QCM system was employed, the quartz crystal of the A-T cut type, exhibiting a fundamental resonant frequency of $10 \mathrm{MHz}$ (Hokuto Denko, Tokyo, Japan). The exposed area of the electrode was $0.07 \mathrm{~cm}^{2}$. The immobilization behavior of PEG-diamine to Ti under charging cathodic potential was investigated using QCM. Platinum was used as the counter electrode and SCE as the reference electrode. In QCM, Ti-QCM electrode was immersed in the PEG-diamine solution for $10 \mathrm{~min}$, followed by charging at -1 and $-3 \mathrm{~V}_{\mathrm{SCE}}$ for $20 \mathrm{~min}$. Meanwhile, the $\Delta f$ of the crystal was stabilized in 0.3 mol L ${ }^{-1} \mathrm{NaCl}$ solution for $10 \mathrm{~min}$ before injection of the PEG-diamine solution. After $10 \mathrm{~min}$, concentrated PEGdiamine solution was injected with a syringe at a concentration of 2 mass $\%$. The $\Delta f$ of the crystal was monitored for $20 \mathrm{~min}$. Whole PEG-diamine molecules adsorbed onto the Ti surface were detected by QCM.

\subsection{Change in the thickness of immobilized layer of PEG-diamine using an ellipsometer}

A commercially pure Ti disk ( $8 \mathrm{~mm} \phi \times 2 \mathrm{~mm}$ in thickness) with grade 2 was metallographically polished and ultrasonically rinsed in acetone, ethanol, and deionized water (Millipore). The Ti disk was fixed in a chamber for simultaneous characterization using the potentiostat and ellipsometer, as illustrated in Fig. 2. The OCP of Ti vs. SCE was measured before electrodeposition. Thereafter, the cathodic potential, $-3 \mathrm{~V}_{\mathrm{SCE}}$, was charged for $300 \mathrm{~s}$, followed by the measurement using the ellipsometer in situ. The thickness of the PEG-diamine layer deposited on Ti was determined with the ellipsometer. These electrodeposition and thickness measurement were repeated four times, respectively. In addition, the anodic potential $+0.1 \mathrm{~V}_{\mathrm{SCE}}$ higher than that of OCP was charged for $300 \mathrm{~s}$, followed by the measurement using the ellipsometer in situ. This process was repeated three times. The experimental flowchart is shown in Fig. 3. The reflective index of the solution was 1.33. The refractive index and absorption coefficient of the Ti substrate in the solution were 2.40 and 3.04 , respectively. 


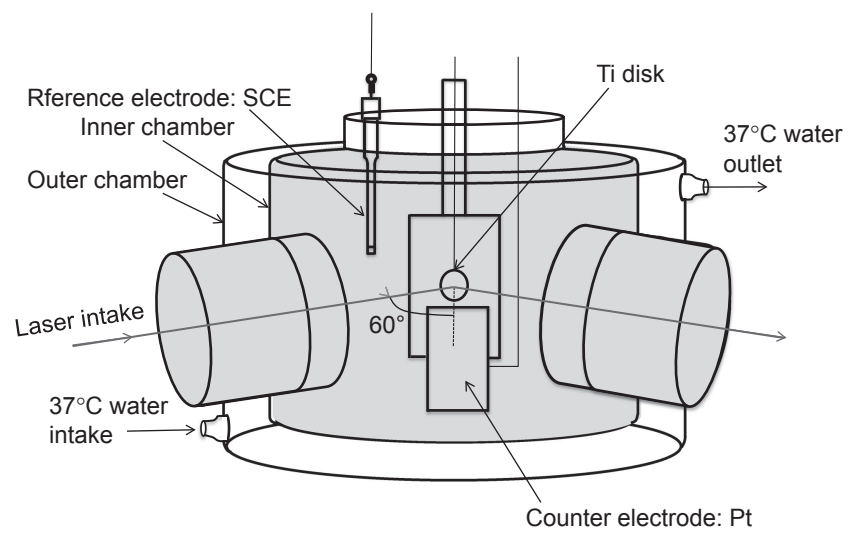

Fig. 2 Electrochemical cell chamber of ellipsometry in situ measurement.

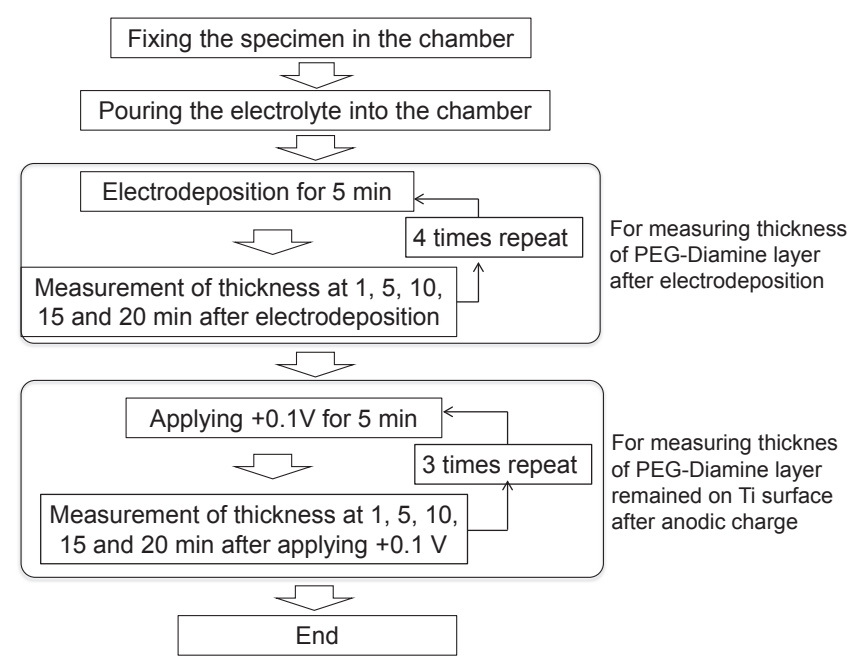

Fig. 3 Flowchart of in situ measurement process of ellipsometry.

\subsection{Change in mass during electric charge using QCM}

For this experiment, besides the above $0.02-\mathrm{mol} \mathrm{L}^{-1}$ PEGdiamine solution $(\mathrm{pH} 11), 2-\mathrm{mol} \mathrm{L}^{-1} \mathrm{NH}_{3}+0.3-\mathrm{mol} \mathrm{L}^{-1}$ $\mathrm{NaCl}$ solution and $0.3-\mathrm{mol} \mathrm{L}^{-1} \mathrm{NaCl}$ solution, adjusted to $\mathrm{pH}$ 11, were employed. In QCM, Ti electrode on quartz was immersed in the above solutions for $10 \mathrm{~min}$, followed by the charging from OCP to $-1.7 \mathrm{~V}_{\mathrm{SCE}}$, with a sweep rate of $2 \times 10^{-3} \mathrm{~V} \mathrm{~s}^{-1}$, and the $\Delta f$ of Ti-QCM electrode at room temperature was monitored.

\subsection{Cathodic polarization}

For this experiment, $0.02-\mathrm{mol} \mathrm{L}^{-1}$ PEG-diamine +0.3 mol L ${ }^{-1} \mathrm{NaCl}$ solutions, $0.01-\mathrm{mol} \mathrm{L}^{-1}$ PEG-diamine +0.3 mol L ${ }^{-1} \mathrm{NaCl}$ solution, $0.02-\mathrm{mol} \mathrm{L}^{-1} \mathrm{NH}_{3}+0.3-\mathrm{mol} \mathrm{L}^{-1}$ $\mathrm{NaCl}$ solution, and $0.3-\mathrm{mol} \mathrm{L}^{-1} \mathrm{NaCl}$ solution, adjusted to $\mathrm{pH}$ 11, were employed. The same Ti desk, as described above, was fixed in a polytetrafluoroethylene holder. The exposed area contacting the electrolyte was $38.5 \mathrm{~mm}^{2}$. Ti disk was immersed in the above solutions for $10 \mathrm{~min}$, followed by charging from OCP to $-1.7 \mathrm{~V}_{\mathrm{SCE}}$, which was the range in which data were obtained stably with a sweep rate of $2 \times 10^{-3} \mathrm{~V} \mathrm{~s}^{-1}$, as a significant outbreak of gas did not occur from the electrodes. The current response was measured using a potentiostat (HAB-501A, Hokuto Denko, Tokyo, Japan).

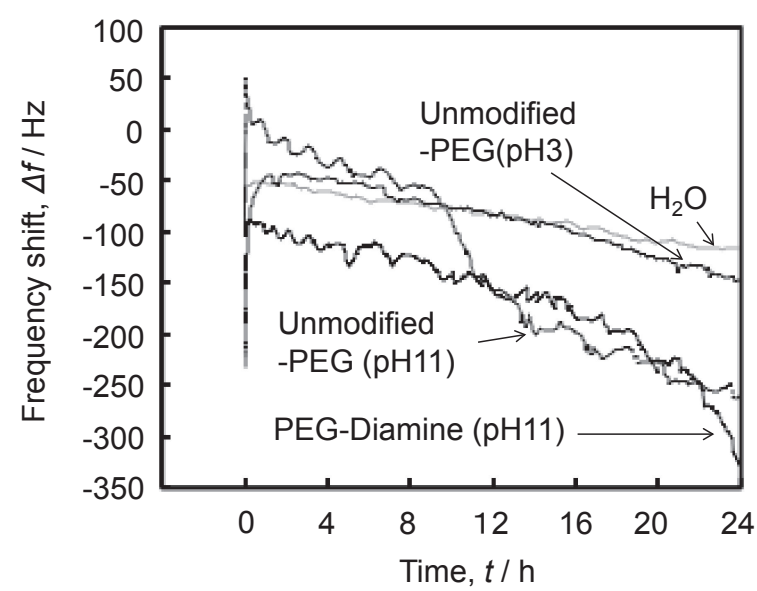

Fig. 4 Time transient of the frequency shift after the injection of each PEGdiamine solution measured by QCM. The decreasing frequency shift indicates the increase in PEG-diamine molecules adsorbed onto the $\mathrm{Ti}$ surface.

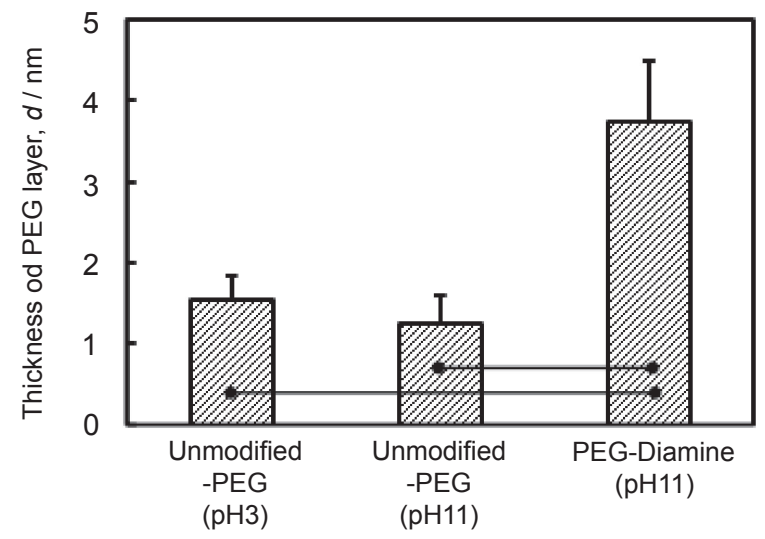

Fig. 5 Thickness of the chemically adsorbed PEG layer on a Ti surface determined by ellipsometry. The bars represent statistically significant differences $(p<0.01)$.

\section{Results}

\subsection{Adsorption behavior of PEG-diamine}

The time transient of the $\Delta f$ after the injection of each solution measured by QCM is shown in Fig. 4. The decreasing $\Delta f$ indicates the increase in mass and/or fluctuation of the adsorbed molecule. Immediately after injection of the PEG-diamine solution, the mass abruptly increased and instantly decreased, followed by a gradual increase. In this experiment, $\Delta f$ represents the mass change due to the adsorption and desorption of PEG-diamine molecules from the Ti surface. More PEG-diamine molecules were adsorbed by $\mathrm{Ti}$ in $\mathrm{pH} 11$ than in $\mathrm{pH} 3$. In addition, $\Delta f$ for Unmodified-PEG and PEG-diamine were almost identical.

The thickness of the remaining PEG-diamine layer on TiQCM electrode immersed in $\mathrm{pH} 11$ solution was much larger than that in $\mathrm{pH} 3$ solution, as shown in Fig. 5. In the case of Unmodified-PEG without termination by amine, the thickness of the adsorbed layer at $\mathrm{pH} 11$ was almost identical to that at $\mathrm{pH} 3$.

\subsection{Adsorption behavior of PEG-diamine}

The mass shift $(\Delta m)$ converted from $\Delta f$ of Ti-QCM 

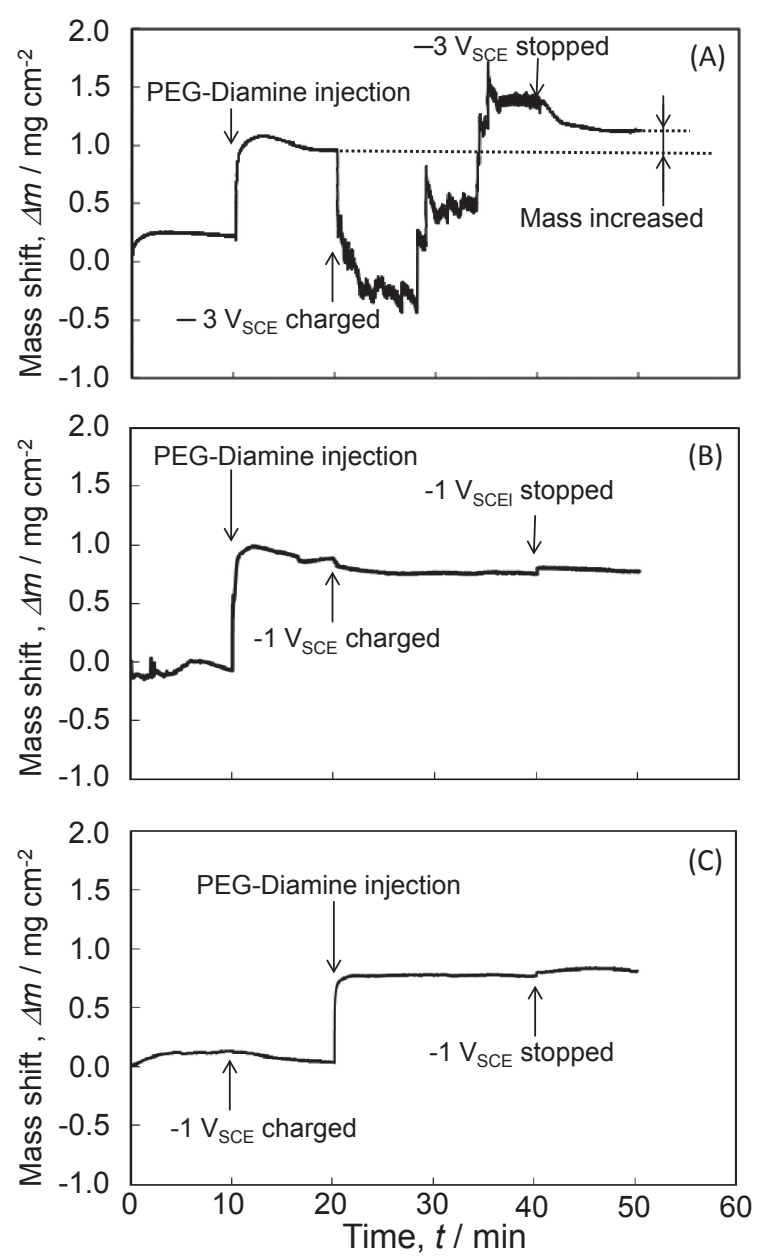

Fig. 6 Mass shift of the PEG-diamine layer on a Ti surface by QCM measurement. (A) $-3 \mathrm{~V}$ vs. SCE potential applied after PEG-diamine injection, (B) $-1 \mathrm{~V}$ vs. SCE potential applied after PEG-diamine injection, and (C) $-1 \mathrm{~V}$ vs. SCE potential applied before PEG-diamine injection.

electrode before and after injection of the concentrated PEGdiamine solution and charging $-3 \mathrm{~V}_{\mathrm{SCE}}$ is shown in Fig. 6(A). Just after the injection of the PEG-diamine solution, the mass abruptly increased, indicating the immediate physical and chemical adsorption of PEG-diamine onto Ti-QCM electrode. After charging $-3 \mathrm{~V}_{\mathrm{SCE}}$, hydrogen evolution from the electrode occurred, and $\mathrm{H}_{2}$ bubbles disturbed the data acquisition. After the termination of electric charging, the mass is measured to be larger than that before electric charging. More PEG-diamine molecules were adsorbed onto the electrode by the cathodic charge.

The $\Delta m$ before and after injection of the concentrated PEG-diamine solution during the charge of $-1 \mathrm{~V}_{\mathrm{SCE}}$ is shown in Fig. 6(B). Just after the injection of the PEG-diamine solution, the mass abruptly increased, indicating that immediately physical and chemical adsorption of PEGdiamine to Ti-QCM electrode occurs. Even after charging $-1 \mathrm{~V}_{\mathrm{SCE}}, \Delta m$ was stable but gradually decreased. This indicates that the PEG-diamine molecules were attracted to Ti-QCM electrode and condensed on the surface without $\mathrm{H}_{2}$ bubbling. The cathodic charge of $-1 \mathrm{~V}_{\mathrm{SCE}}$ did not adsorb any extra PEG-diamine molecules because of its weak attracted force. After the termination of electric charging, the mass slightly increased owing to the relaxation from the attractive force to Ti-QCM electrode.

The $\Delta m$ of Ti-QCM electrode cathodically charged $-1 \mathrm{~V}_{\mathrm{SCE}}$, and the injection of the concentrated PEG-diamine solution is shown in Fig. 6(C). When the Ti-QCM electrode was cathodically charged, no mass change was observed, because PEG-diamine molecule was absent. Just after injection of the PEG-diamine solution, the mass abruptly increased, indicating the immediate physical and chemical adsorption of PEG-diamine to Ti-QCM electrode. After the termination of electric charging, the mass slightly increased owing to the relaxation from the attractive force to Ti-QCM electrode.

\subsection{Change in the thickness of immobilized layer of PEG-diamine using an ellipsometer}

The change in the thickness of the PEG-diamine layer on Ti electrode at 5, 10, 15, and 20 min after electrodeposition measured in situ by the ellipsometer is shown in Fig. 7. The thickness at $5 \mathrm{~min}$ after electrodeposition could not be measured. The thickness increased with electrodeposition time. More electrodeposited PEG-diamine molecules corresponded to longer cathodic potential charging time. After electrodeposition, the thickness increased once at $5 \mathrm{~min}$, followed by a gradual decrease.

The change in the thickness of the PEG-diamine layer by the anodic potential charge is shown in Fig. 8. After electrodeposition of PEG-diamine molecules to Ti electrode with $-3 \mathrm{~V}_{\mathrm{SCE}}$ for $5 \mathrm{~min}$ four times and the termination of electric charging, the thickness of the molecular layer increased once and then gradually decreased, as mentioned above. After $30 \mathrm{~min}$ remaining, an anodic potential $+0.1 \mathrm{~V}_{\mathrm{SCE}}$ higher than that of OPC was charged for $5 \mathrm{~min}$, and left for $20 \mathrm{~min}$. Despite repeating this process, the thickness did not change by charging the anodic potential.

\subsection{Change in mass during electric charge}

The change in the $\triangle m$ of Ti-QCM electrode in the PEGdiamine solution when the potential decreased from OCP to $-1.7 \mathrm{~V}_{\mathrm{SCE}}$ and increased to $-0.5 \mathrm{~V}_{\mathrm{SCE}}$ is shown in Fig. 9(A). Fluctuation on the cathodic polarization curve was caused by $\mathrm{H}_{2}$ gas bubbling by hydrogen evolution, decreasing once

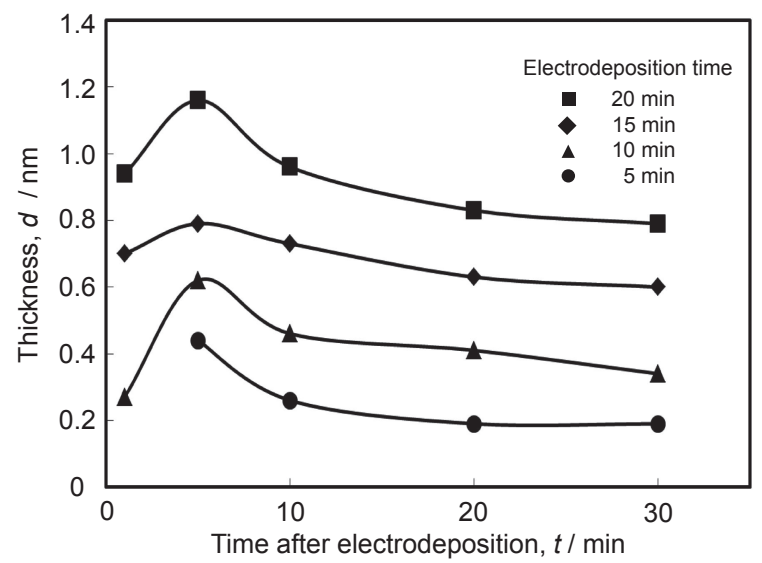

Fig. 7 Change in the thickness of the PEG-diamine layer on Ti surface after electrodeposition for $1,5,10,15$, and $20 \mathrm{~min}$ determined by ellipsometry in situ measurement. 


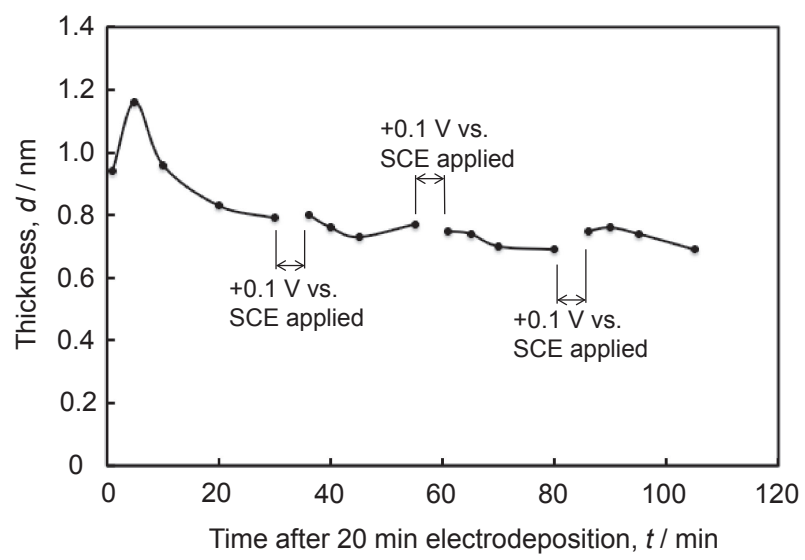

Fig. 8 Thickness shift of the PEG-diamine layer on a Ti surface after 20-min electrodeposition and application of $+0.1 \mathrm{~V}$ vs. SCE.
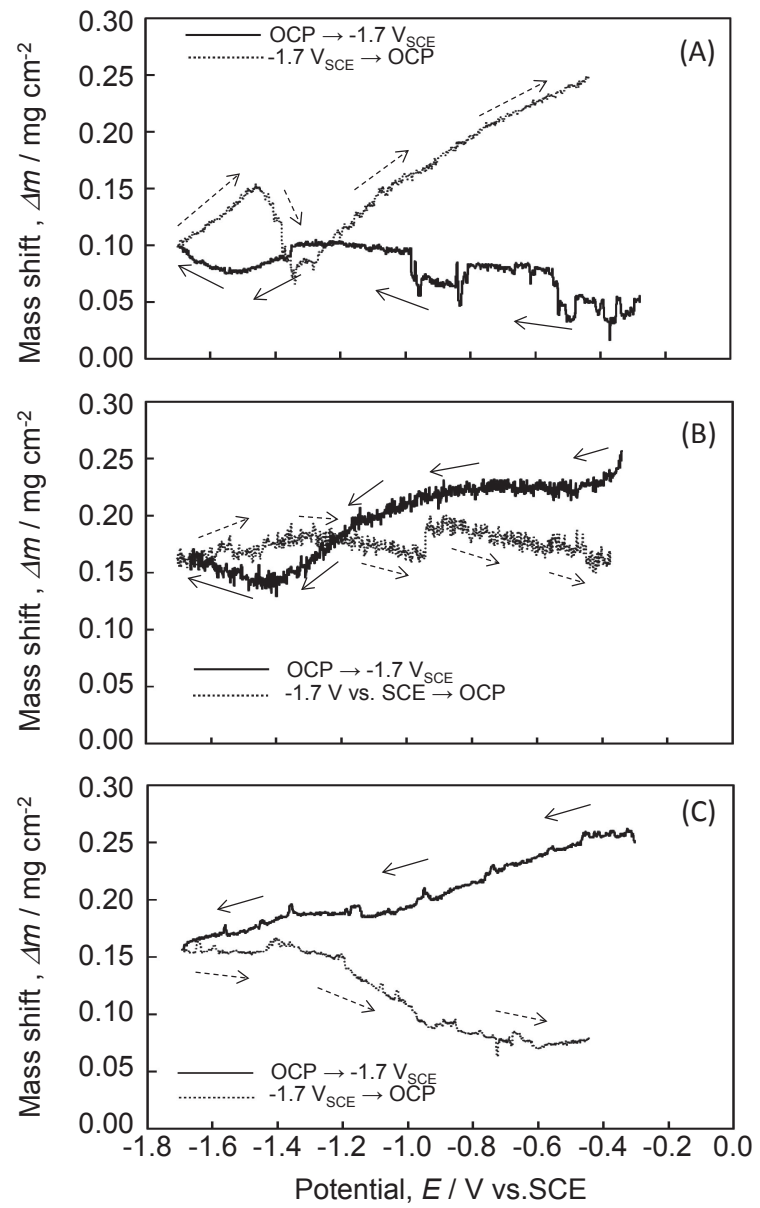

Fig. 9 Mass shift applied potential between open circuit potential and $-1.7 \mathrm{~V}$ vs. SCE in (A) PEG-diamine $+\mathrm{NaCl}$ solution, (B) in $\mathrm{NH}_{3(\mathrm{aq})}+$ $\mathrm{NaCl}$ solution, and (C) $\mathrm{NaCl}$ solution measured by QCM.

on the anodic polarization curve at $-1.3 \mathrm{~V}_{\mathrm{SCE}}$. The mass gradually increased with cathodic polarization from OCP to $-1.4 \mathrm{~V}_{\mathrm{SCE}}$, increasing more significantly with cathodic charge from -1.4 to $-1.7 \mathrm{~V}_{\mathrm{SCE}}$ and continuously increased with anodic polarization from -1.7 to $-0.5 \mathrm{~V}_{\mathrm{SCE}}$.

The change in the $\Delta m$ of Ti-QCM electrode in the $\mathrm{NH}_{3}+\mathrm{NaCl}$ solution when the potential decreased from OCP to $-1.7 \mathrm{~V}_{\mathrm{SCE}}$ and increased to $-0.3 \mathrm{~V}_{\mathrm{SCE}}$ is shown in Fig. 9(B). The mass decreased with cathodic polarization

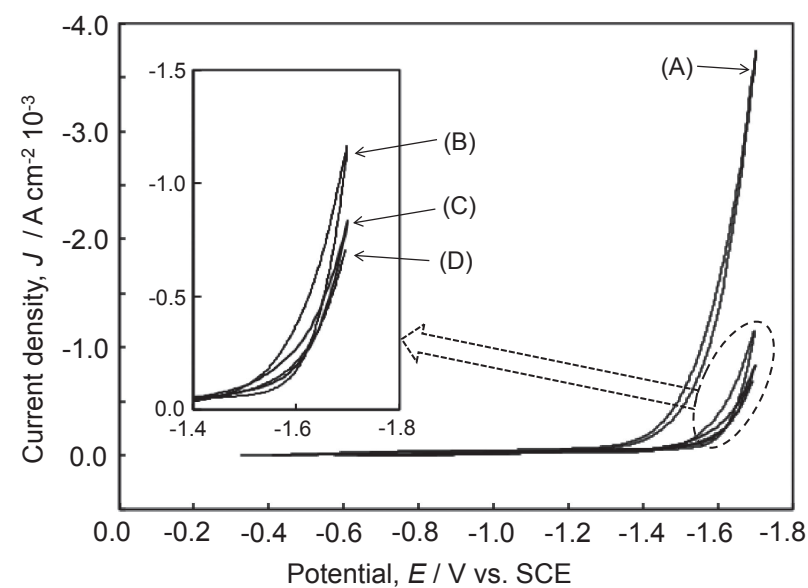

Fig. 10 Cyclic voltammetry curve of $\mathrm{Ti}$ in (A) $0.02-\mathrm{mol} \mathrm{L}^{-1} \mathrm{NH}_{3}+$ $0.3-\mathrm{mol} \mathrm{L}^{-1} \mathrm{NaCl}$ solution, (B) $0.02-\mathrm{mol} \mathrm{L}^{-1}$ PEG-diamine $+0.3-$ $\mathrm{mol} \mathrm{L}^{-1} \mathrm{NaCl}$ solution, (C) $0.01-\mathrm{mol} \mathrm{L}^{-1}$ PEG-diamine $+0.3-\mathrm{mol} \mathrm{L}^{-1}$ $\mathrm{NaCl}$ solution, and (D) $0.3-\mathrm{mol} \mathrm{L}^{-1} \mathrm{NaCl}$ solution, adjusted to $\mathrm{pH} 11$.

from OCP to $c a$. $-1.4 \mathrm{~V}_{\mathrm{SCE}}$ and increased to $-1.7 \mathrm{~V}_{\mathrm{SCE}}$. The mass also increased after anodic polarization until $-1.4 \mathrm{~V}_{\mathrm{SCE}}$ and decreased until $-0.3 \mathrm{~V}_{\mathrm{SCE}}$.

The change in the $\Delta m$ of Ti-QCM electrode in $\mathrm{NaCl}$ solution when the potential decreased from OCP to $-1.7 \mathrm{~V}_{\mathrm{SCE}}$ and increased to $-0.4 \mathrm{~V}_{\mathrm{SCE}}$ is shown in Fig. 9(C). The mass decreased with cathodic charge from OCP to ca. $-1.7 \mathrm{~V}_{\mathrm{SCE}}$ and continuously decreased to $-0.4 \mathrm{~V}_{\mathrm{SCE}}$ on anodic polarization.

\subsection{Cathodic polarization}

Polarization curves by cyclic voltammetry from OCP to $-1.7 \mathrm{~V}_{\mathrm{SCE}}$ represented by an actual amount of current are shown in Fig. 10. From OCP to $-1.3 \mathrm{~V}_{\mathrm{SCE}}$, all curves overlap. From approximately $-1.3 \mathrm{~V}_{\mathrm{SCE}}$, the current density in solution with $\mathrm{NH}_{3}$ molecules increased and reached the highest current density value among the four types of solutions at $-1.7 \mathrm{~V}_{\mathrm{SCE}}$ (Fig. 10(A)). The current density in two types of solutions with $\mathrm{PEG}$-diamine and $\mathrm{NaCl}$ solution without either PEG-diamine or $\mathrm{NH}_{3}$ molecules increased from approximately $-1.5 \mathrm{~V}_{\mathrm{SCE}}$. These current density values were lower than those in $\mathrm{NH}_{3}$ solution. Comparing current density values in these three solutions at $-1.7 \mathrm{~V}_{\mathrm{SCE}}, 0.02-$ mol L ${ }^{-1}$ PEG-diamine was the highest (Fig. 10(B)) and the second highest was 0.01-mol L ${ }^{-1}$ PEG-diamine (Fig. 10(C)), whereas $\mathrm{NaCl}$ solution without either PEG-diamine or $\mathrm{NH}_{3}$ molecules was the lowest (Fig. 10(D)).

Cathodic polarization curves of $\mathrm{Ti}$ in the PEG-diamine solution and $\mathrm{NaCl}$ solution without PEG-diamine molecules from OCP to $-1.7 \mathrm{~V}_{\mathrm{SCE}}$, represented by an actual amount of current density, are shown in Fig. 11(A). From OCP to $-1.4 \mathrm{~V}_{\mathrm{SCE}}$, both curves overlap. From -1.4 to $-1.6 \mathrm{~V}_{\mathrm{SCE}}$, the current density in solution with PEG-diamine molecules was smaller than that without molecules. Meanwhile, from -1.6 to $-1.7 \mathrm{~V}_{\mathrm{SCE}}$, the current density in solution with PEGdiamine molecules was larger than that without molecules. From -1.4 to $-1.6 \mathrm{~V}_{\mathrm{SCE}}$, PEG-diamine molecules were physically and chemically adsorbed, working as a barrier, and the resulting electric resistance increased, inducing a decrease in the current in the PEG-diamine solution. From -1.6 to 


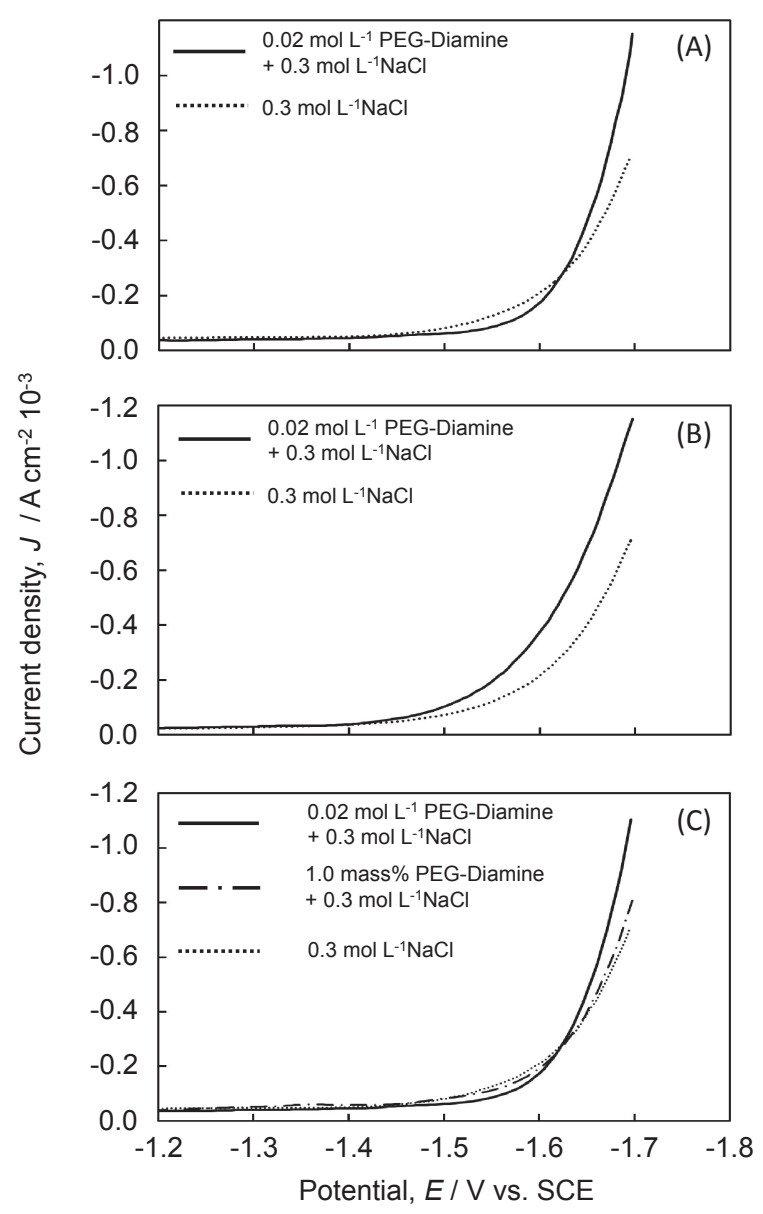

Fig. 11 Cyclic voltammetry curve of 2 mass $\%$ PEG-diamine +0.3 $\mathrm{molL}^{-1} \mathrm{NaCl}, 0.3-\mathrm{molL}^{-1} \mathrm{NaCl}$ electrolyte, and $0.3-\mathrm{mol} \mathrm{L}^{-1} \mathrm{NaCl}$ electrolyte (A) from open circuit potential to $-1.7 \mathrm{~V}$ vs. SCE, (B) from $-1.7 \mathrm{~V}$ vs. SCE to open circuit potential, and (C) three types of electrolyte, 1 mass \% PEG-diamine $+0.3-\mathrm{mol} \mathrm{L}^{-1} \mathrm{NaCl}, 2$ mass $\%$ PEGdiamine $+0.3-\mathrm{mol} \mathrm{L}^{-1} \mathrm{NaCl}$, and $0.3-\mathrm{mol} \mathrm{L}^{-1} \mathrm{NaCl}$ from OCP to $-1.7 \mathrm{~V}$ vs. SCE.

$-1.7 \mathrm{~V}_{\mathrm{SCE}}$, the electrode reaction relating to PEG-diamine molecules generated a larger cathodic current in the solution with PEG-diamine molecules than that without PEG-diamine.

Meanwhile, polarization curves of $\mathrm{Ti}$ in the PEG-diamine solution and $\mathrm{NaCl}$ solution without PEG-diamine molecules from $-1.7 \mathrm{~V}_{\mathrm{SCE}}$ to $\mathrm{OCP}$, represented by an actual amount of current density, are shown in Fig. 11(B). From -1.7 to $-1.4 \mathrm{~V}_{\mathrm{SCE}}$, the current density in solution with PEG-diamine molecules was larger than that without PEG-diamine. Therefore, anodic polarization induced a different Ti surface state from the charging cathodic current. PEG-diamine molecules are clearly and consecutively influenced by the electrode reaction.

\section{Discussion}

As indicated by Fig. 4, more PEG-diamine molecules were adsorbed by $\mathrm{Ti}$ in $\mathrm{pH} 11$ than in $\mathrm{pH} 3$. In addition, the $\Delta f$ in Unmodified-PEG and PEG-diamine were almost the same. The adsorbed molecule mass in $\mathrm{pH} 11$ was estimated as $4.1 \mu \mathrm{g} \mathrm{cm}^{-2}$ corresponding to approximately 25 molecules per $\mathrm{nm}^{2}$. The concentration of active hydroxyl groups on Ti is $12 \mathrm{~nm}^{-2}$. $\left.^{25}\right)$ Therefore, no adsorbed molecules existed on the first layer of the Ti substrate but rather on the second and over layers, whose bonding force was possibly weak. Meanwhile, the adsorbed amount was relatively small in $\mathrm{pH}$ 3. The point of zero charge of $\mathrm{TiO}_{2}$, covering $\mathrm{Ti}$, is 6.7 in the case of anatase and 5.2 for rutile. ${ }^{26)}$ Therefore, the Ti surface is positively charged at $\mathrm{pH} 3$ and negatively charged at $\mathrm{pH}$ 11. PEG-diamine molecules are positively charged in solution. Meanwhile, despite the lack of electric charge on Unmodified-PEG, the electrostatic force for adsorption between these molecules and Ti surface was much larger at $\mathrm{pH} 11$ than at $\mathrm{pH}$ 3. The surface electric charge of $\mathrm{Ti}$ substrate directly influences the adsorption of PEG-diamine and Unmodified-PEG molecules. In the case of UnmodifiedPEG without termination with amine, the thickness of the adsorbed layer at $\mathrm{pH} 11$ was almost the same as that at $\mathrm{pH} 3$ (Fig. 5). This indicates that Unmodified-PEG does not have a sufficient amount of electric charge to remain on the $\mathrm{Ti}$ surface under rinsing in deionized water, and the adsorption is not influenced by $\mathrm{pH}$ or surface electric charge of Ti. Meanwhile, the thickness of Unmodified-PEG was much smaller than that of PEG-diamine at $\mathrm{pH} \mathrm{11,} \mathrm{whereas} \mathrm{the} \Delta f$ in the case of the QCM of Unmodified-PEG and that of PEG-diamine were the almost same. PEG-diamine molecules were both physically and chemically adsorbed onto $\mathrm{Ti}$, because the molecule was positively charged, and the $\mathrm{Ti}$ surface was negatively charged. Although Unmodified-PEG molecules undergo polarization due to hydroxyl groups, its effect is very small. These molecules were only physically adsorbed onto Ti surface. Therefore, before ellipsometry was performed, more Unmodified-PEG molecules were removed during rinsing, whereas more PEG-diamine molecules remained. The thickness of Unmodified-PEG was eventually much smaller than that of PEG-diamine at pH 11.

As observed in Fig. 6, the immediate physical and chemical adsorption of PEG-diamine to Ti-QCM electrode occurred just after the immersion of $\mathrm{Ti}$ in PEG-diamine solution; further, more PEG-diamine molecules were adsorbed onto the electrode by the cathodic charge.

By measuring the change in the thickness of the immobilized layer of PEG-diamine using an ellipsometer (Fig. 7), it was revealed that PEG-diamine molecules were physically and chemically adsorbed by Ti electrode, attracted to the surface, and condensed on the surface. More PEGdiamine molecules were attracted to the surface during electrodeposition. After the termination of electrodeposition, bound molecules were at once relieved and swelled, inducing the apparent increase in the thickness. Thereafter, physically adsorbed molecules in the outside of PEG-diamine layer were gradually separated from the surface, and the apparent thickness decreased with time for convergence to a certain value. PEG-diamine molecules once electrodeposited were not detached from the Ti electrode by the charging anodic potential (Fig. 8). In other words, the bonding of PEGdiamine molecules to the Ti surface by electrodeposition was strong and did not detach by anodic potential charge.

In Fig. 9(A), PEG-diamine molecules immobilized by electrodeposition with a cathodic charge to $-1.7 \mathrm{~V}_{\mathrm{SCE}}$ were condensed on the Ti-QCM electrode surface. This condensation appeared as the increase in mass, and this tendency 
clearly appeared from -1.4 to $-1.7 \mathrm{~V}_{\mathrm{SCE}}$. This apparent increase in mass continued, even after the commencement of anodic polarization because immobilized and condensed PEG-diamine molecules swelled with the decrease in cathodic potential. In the case of $\mathrm{NH}_{3}$, immobilization of $\mathrm{NH}_{3}$ occurred from $-1.4 \mathrm{~V}_{\mathrm{SCE}}$ in cathodic polarization along with that of PEG-diamine. In anodic polarization, the immobilization continued until $-1.4 \mathrm{~V}_{\mathrm{SCE}}$ and disappeared over $-1.4 \mathrm{~V}_{\mathrm{SCE}}$ (Fig. 9(B)). Because $\mathrm{NH}_{3}$ is the minimum unit of amine and does not swell, unlike PEG-diamine molecule, the influence of the swelling of $\mathrm{NH}_{3}$ molecules was very small. The increase in the net mass with electrodeposition occurred in the potential range between $-1.4 \mathrm{~V}_{\mathrm{SCE}}$ and $-1.7 \mathrm{~V}_{\mathrm{SCE}}$. However, there was no clear increase in the mass in the QCM measurement in $\mathrm{NaCl}$ solution without PEG-diamine and $\mathrm{NH}_{3}$ (Fig. 9(C)). This result supports the increase in mass with the immobilization of PEG-diamine and $\mathrm{NH}_{3}$ molecules.

In Fig. 10, the current density was influenced by the molecules in the electrolyte. The existence of molecules with amino group in the solution caused an increase in the current density. In relation to the two different solutions of PEGdiamine, higher concentration of these molecules corresponded to a higher current density. This indicates that the amino group received electrons from the cathodic electrode.

Here, we attempt to estimate the quantity of electricity that increased by existence of the PEG-diamine molecules in the electrolyte of cyclic voltammetry. In the ranges from -1.6 to $-1.7 \mathrm{~V}_{\mathrm{SCE}}$ and -1.7 to $-1.4 \mathrm{~V}_{\mathrm{SCE}}$, the current density measured in the solution with PEG-diamine molecules was larger than that without PEG-diamine molecules. The cyclic voltammetry curves were approximated by an exponential function as

$$
J=a e^{b E}
$$

where $J$ is current density $\left(\mathrm{Acm}^{-2}\right), E$ is potential $(\mathrm{V}), e$ is Napier's constant, and $\mathrm{a}$ and $\mathrm{b}$ are constants. Meanwhile, potential $E$ in eq. (1) is related to time $t$ as

$$
E=c t
$$

where $c$ is sweep ratio $\left(\mathrm{V} \mathrm{sec}^{-1}\right)$ equal to $2 \times 10^{-3} \mathrm{~V} \mathrm{~s}^{-1}$. Therefore,

$$
J=a e^{b c t} .
$$

The amount of electricity per unit area $Q\left(\mathrm{C} \mathrm{cm}^{-2}\right)$ consumed by the cathodic electrode reaction in the range from $E_{1}$ (time: $\left.t_{1}\right)$ to $E_{2}$ (time: $t_{2}$ ) is as follows:

$$
Q=\int_{t_{1}}^{t_{2}} J d t=\int_{\frac{E_{1}}{c}}^{\frac{E_{2}}{c}} a e^{b c t} d t=\frac{a}{b c}\left[e^{\frac{b c E_{2}}{c}}-e^{\frac{b c E_{1}}{c}}\right] .
$$

Subscripts "PEG1" and "PEG2" refer to the potential range from -1.6 to $-1.7 \mathrm{~V}_{\mathrm{SCE}}$ and -1.7 to $-1.4 \mathrm{~V}_{\mathrm{SCE}}$ in the solution with PEG-diamine molecules, respectively. Current densities $J_{\mathrm{PEG} 1}$ and $J_{\mathrm{PEG} 2}$ were approximated as follows:

$$
\begin{aligned}
& J_{\mathrm{PEG} 1}=-8.43 \times 10^{-18} \cdot e^{-19.2 E}\left(\mathrm{R}^{2}=0.999\right) \\
& J_{\mathrm{PEG} 2}=-1.65 \times 10^{-12} \cdot e^{-12.0 E}\left(\mathrm{R}^{2}=0.997\right)
\end{aligned}
$$

where $R$ is the correlation coefficient.

The total quantity of electricity per unit area $Q_{\mathrm{PEG}}$ in the solution with PEG-diamine molecules in the potential ranges from -1.6 to $-1.7 \mathrm{~V}_{\mathrm{SCE}}$ and -1.7 to $-1.4 \mathrm{~V}_{\mathrm{SCE}}$ was calculated as follows:

$$
\begin{aligned}
Q_{\mathrm{PEG}}= & \int_{\frac{-1.6}{2 \times 10^{-3}}}^{\frac{-1.7}{2 \times 10^{-3}}}\left(-8.43 \times 10^{-18}\right) e^{-19.2 \times 2 \times 10^{-3} t} d t \\
& +\int_{\frac{-1.4}{2 \times 10^{-3}}}^{\frac{-1.7}{2 \times 10^{-3}}}\left(-1.65 \times 10^{-12}\right) e^{-12.0 \times 2 \times 10^{-3} t} d t \\
= & \left(-2.70 \times 10^{-2}\right)+\left(-4.88 \times 10^{-2}\right) \\
= & -7.58 \times 10^{-2}\left(\mathrm{C} \mathrm{cm}^{-2}\right) .
\end{aligned}
$$

Subscripts "NO1" and "NO2" refer to the potential ranges from -1.6 to $-1.7 \mathrm{~V}_{\mathrm{SCE}}$ and -1.7 to $-1.4 \mathrm{~V}_{\mathrm{SCE}}$ in the solution without PEG-diamine molecules, respectively. Current densities $J_{\mathrm{NO} 1}$ and $J_{\mathrm{NO} 2}$ were approximated as

$$
\begin{aligned}
& J_{\mathrm{NO} 1}=-1.13 \times 10^{-13} \cdot e^{-13.3 E}\left(\mathrm{R}^{2}=0.999\right) \\
& J_{\mathrm{NO} 2}=-1.41 \times 10^{-11} \cdot e^{-10.4 E}\left(\mathrm{R}^{2}=0.987\right)
\end{aligned}
$$

The total quantity of electricity per unit area $Q_{\mathrm{NO}}$ in the solution without PEG-diamine molecules in the potential ranges from -1.6 to $-1.7 \mathrm{~V}_{\mathrm{SCE}}$ and -1.7 to $-1.4 \mathrm{~V}_{\mathrm{SCE}}$ was calculated as follows:

$$
\begin{aligned}
Q_{\mathrm{NO}}= & \int_{\frac{-1.6}{2 \times 10^{-3}}}^{\frac{-1.7}{2 \times 10^{-3}}}\left(-1.13 \times 10^{-13}\right) e^{-13.3 \times 2 \times 10^{-3} t} d t \\
& +\int_{\frac{-1.4}{2 \times 10^{-3}}}^{\frac{-1.7}{2 \times 10^{-3}}}\left(-1.41 \times 10^{-11}\right) e^{-10.4 \times 2 \times 10^{-3} t} d t \\
= & \left(-2.09 \times 10^{-3}\right)+\left(-2.96 \times 10^{-2}\right) \\
= & -5.05 \times 10^{-2}\left(\mathrm{C} \mathrm{cm}^{-2}\right) .
\end{aligned}
$$

Therefore, the electrical quantity $\Delta Q$, which increased with the existence of PEG-diamine molecules in solution, is calculated as follows:

$$
\begin{aligned}
\Delta Q & =Q_{\mathrm{PEG}}-Q_{\mathrm{NO}}=-7.58 \times 10^{-2}-\left(-5.05 \times 10^{-2}\right) \\
& =-2.53 \times 10^{-2}\left(\mathrm{C} \mathrm{cm}^{-2}\right) .
\end{aligned}
$$

This $\Delta Q$ was converted to the number of electrons per $\mathrm{nm}^{2}$, $N$, which was consumed by the electrode reaction related to PEG-diamine molecules,

$$
N=1.58 \times 10^{3}\left(\mathrm{~nm}^{-2}\right) .
$$

Meanwhile, it is known that the concentration of hydroxyl groups on the surface oxide layer of $\mathrm{Ti}$ is $c a .12 \mathrm{~nm}^{-2} \cdot{ }^{25}$ ) Therefore, most of the electrons are considered to be consumed in the electrode reactions in addition to the reaction between these hydroxyl groups and PEG-diamine molecules.

The ionization equilibrium equation of PEG-diamine is as follows:

$$
\mathrm{NH}_{2}-\mathrm{PEG}-\mathrm{NH}_{2}+2 \mathrm{H}_{2} \mathrm{O} \leftrightarrows \mathrm{NH}_{3}^{+}-\mathrm{PEG}-\mathrm{NH}_{3}^{+}+2 \mathrm{OH}^{-}
$$

Because, the $\mathrm{pH}$ of 2 mass\% PEG-diamine solution was 11.3, its electrolytic dissociation constant was estimated as $1.94 \times 10^{-7}$, with $5.0 \%$ of PEG-diamine ionized. Considering that the molecules of PEG-diamine are attracted to the surface of the cathode electrode, the reaction in which PEGdiamine molecules received electrons may proceed as follows: 
(A)

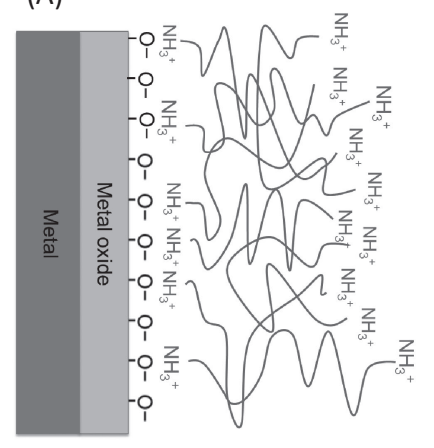

(B)

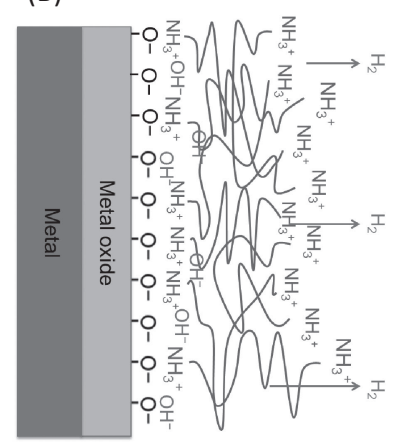

(C)

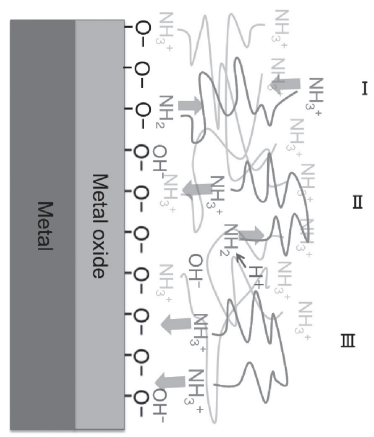

(D)

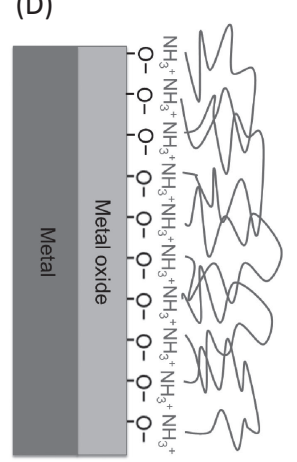

Fig. 12 Immobilization mechanism of PEG-diamine molecule to titanium surface.

$$
\mathrm{NH}_{3}^{+}-\mathrm{PEG}-\mathrm{NH}_{3}^{+}+2 e^{-} \rightarrow \mathrm{NH}_{2}-\mathrm{PEG}-\mathrm{NH}_{2}+\mathrm{H}_{2} \text {. }
$$

In this reaction, PEG-diamine molecules catalytically enhanced hydrogen evolution. ${ }^{27)}$

In this electrodeposition process, because $\mathrm{Ti}$ disk was immersed into the solution with PEG-diamine molecules to measure OCP before electrodeposition, it is considered that amines randomly exist as $\mathrm{NH}_{3}{ }^{+}$in the $\mathrm{PEG}$ molecule groups (Fig. 12(A)). As soon as $-3 \mathrm{~V}_{\mathrm{SCE}}$ is applied, the layer of PEG-diamine molecules condensed on the Ti surface, hydrogen was generated, and the $\mathrm{pH}$ increased near the $\mathrm{Ti}$ surface (Fig. 12(B)). Ionizing PEG-diamine molecules lost electric charge at one instance, and the electrostatic force between PEG-diamine molecule and hydroxyl group on the Ti surface oxide became weak (Fig. 12(C)-I). PEGdiamine molecules are slightly separated from the Ti surface. These molecules ionize again because of decreasing $\mathrm{pH}$ (Fig. 12(C)-II) and immobilize on the Ti surface again (Fig. 12(C)-III). In this manner, PEG-diamine molecules do not tightly remain on the Ti surface under electrodeposition but shake around the Ti surface while undergoing repeated ionization and un-ionization. Because of these motions of PEG-diamine molecules near the Ti surface, the structure of the PEG-diamine layer is assumed to rearrange to a U-shape structure (Fig. 12(D)).

\section{Conclusion}

Surface electric charge directly influenced the adsorption of PEG molecule in which both terminals of PEG were terminated with $\mathrm{NH}_{2}$ (PEG-diamine) and Unmodified-PEG molecules. PEG-diamine molecules were attracted to the Ti-QCM electrode and condensed on the surface. After the termination of electric charging, the relaxation from the attractive force to the Ti-QCM electrode occurred. Bonding of the PEG-diamine molecules with the Ti surface by electrodeposition was strong and did not detach by anodic potential charge. PEG-diamine was immediately adsorbed onto the Ti surface by electrostatic force with a weak force in a random manner, and rearranged and condensed on the Ti surface with electrochemical reactions between the molecules and $\mathrm{Ti}$ surface by cathodic electric charge. In this manner, PEG-diamine molecules do not tightly remain on the Ti surface under electrodeposition but shake around the $\mathrm{Ti}$ surface while undergoing repeated ionization and unionization. The elucidation of this electrodeposition mechanism will help reveal the electrodeposition phenomenon of other biofunctional molecules to metal surfaces.

\section{Acknowledgements}

This work was supported by Grant-in-Aid for Scientific Research (A) No. 22240059 from the Japan Society for the Promotion of Science (JSPS). This study was also supported by the projects "Cooperative project amount medicine, dentistry, and engineering for medical innovation-Construction of creative scientific research of the viable material via integration of biology and engineering" and "Creation of Life Innovation Materials for Interdisciplinary and International Researcher Development (iLIM)" by the Ministry of Education, Culture, Sports, Science and Technology, Japan.

\section{REFERENCES}

1) D.M. Brunette, P. Tenvall, M. Textor and P. Thomsen: Titanium in Medicine, (Springer, Berlin, 2000) pp. 231-455.

2) T. Hanawa: J. R. Soc. Interface 6 (2009) S361-S369.

3) T. Hanawa: Titanium in Medical and Dental Applications, ed. by F.H. Froes and M. Qian, (Woodhead Publishing, Cambridge, 2017) pp. 95114.

4) R. Williams: Surface Modification of Biomaterials, (Woodhead Publishing, Cambridge, 2011).

5) B.D. Ratner, A.S. Hoffman, F.J. Schoen and J.E. Lemons (ed.): Biomaterials Science-An Introduction to Materials in Medicine, 3rd ed., (Academic Press, Oxford, 2013) pp. 120-124.

6) A. Civantos, E. Martinez-Campos, V. Ramos, C. Elvira, A. Gallardo and A. Abarrategi: ACS Biomater. Sci. Eng. 3 (2017) 1245-1261.

7) T. Hanawa: Front. Bioeng. Biotechnol. 7 (2019) 170.

8) T. Hanawa: Polymeric Biomaterials: Structure and Function, Volume 1, ed. by S. Dumitriu and V. Popa, (CRC Press, Boca Raton, 2013) p. 343 .

9) R.I. Mahato: Biomaterials for Delivery and Targeting of Proteins and Nucleic Acids, (CRC Press, Boca Raton, 2005).

10) Y. Tanaka, H. Doi, Y. Iwasaki, S. Hiromoto, T. Yoneyama, K. Asami, H. Imai and T. Hanawa: Mater. Sci. Eng. C 27 (2007) 206-212.

11) Y. Tanaka, H. Doi, E. Kobayashi, T. Yoneyama and T. Hanawa: Mater. Trans. 48 (2007) 287-292.

12) Y. Tanaka, H. Saito, Y. Tsutsumi, H. Doi, H. Imai and T. Hanawa: Mater. Trans. 49 (2008) 805-811.

13) Y. Tanaka, Y. Matsuo, T. Komiya, Y. Tsutsumi, H. Doi, T. Yoneyama and T. Hanawa: J. Biomed. Mater. Res. 92A (2010) 350-358.

14) Y. Tanaka, K. Matin, M. Gyo, A. Okada, Y. Tsutsumi, H. Doi, N. Nomura, J. Tagami and T. Hanawa: J. Biomed. Mater. Res. 95A (2010) 1105-1113.

15) A. Kawabe, I. Nakagawa, Z. Kanno, Y. Tsutsumi, T. Hanawa and T. Ono: Dent. Mater. J. 33 (2014) 638-647. 
16) Y. Tanaka, H. Saito, Y. Tsutsumi, H. Doi, N. Nomura, H. Imai and T Hanawa: J. Colloid Interface Sci. 330 (2009) 138-143.

17) K. Oya, Y. Tanaka, H. Saito, K. Kurashima, K. Nogi, H. Tsutsumi, Y Tsutsumi, H. Doi, N. Nomura and T. Hanawa: Biomaterials 30 (2009) 1281-1286.

18) J.W. Park, K. Kurashima, Y. Tustusmi, C.H. An, J.Y. Suh, H. Doi, N. Nomura, K. Noda and T. Hanawa: Acta Biomater. 7 (2011) 3222-3229.

19) J.H. Seo, Y. Tsutsumi, A. Kobari, M. Shimojo, T. Hanawa and N. Yui: Soft Mater. 11 (2015) 936-942.

20) Y. Fukuhara, M. Kyuzo, Y. Tsutsumi, A. Nagai, P. Chen and T. Hanawa: Appl. Surf. Sci. 355 (2015) 784-791.

21) Y. Fukuhara, M. Kyuzo, Y. Tsutsumi, A. Nagai, P. Chen and T.
Hanawa: J. Biomed. Mater. Res. Part B: Appl. Biomater. 104 (2016) 554-560.

22) CRC Handbook of Chemistry and Physics, 67th ed., (CRC Press, Boca Raton, 1986) p. E-390.

23) E.D. Palik (ed.): Handbook of Optical Constants of Solids, (Academic Press, New York, 1985) pp. 233-249.

24) E.D. Palik (ed.): Handbook of Optical Constants of Solids, (Academic Press, New York, 1985) pp. 795-804.

25) J. Westall and H. Hohl: Adv. Colloid Interface Sci. 12 (1980) 265-294.

26) G.D. Parfitt: Prog. Surf. Membr. Sci. 11 (1976) 181-226.

27) M. Noel, C. Ravichandran and P.N. Anantharaman: J. Appl. Electrochem. 25 (1995) 690-698. 